\title{
A AFINAÇÃO “PELAS TRÊS" DA VIOLA FANDANGUEIRA DE MORRETES NO ESTADO PARANÁ
}

\section{"PELAS TRÊS" TUNING ON THE VIOLA FANDANGUEIRA FROM MORRETES IN PARANÁ}

\author{
Frederico Conçalves Pedrosa \\ Universidade Estadual do Paraná (campus II - FAP) \\ frederico.musicoterapia@gmail.com
}

\section{Resumo}

O presente artigo trata de um estudo sobre o fandango do município de Morretes, no Estado do Paraná (PR), tendo como marco teórico da pesquisa a obra A arte de pontear viola (2002), do Professor Doutor Roberto Nunes Corrêa. A esta pesquisa soma-se um estudo descritivo do processo de autoaprendizagem, desenvolvido pelo próprio pesquisador, a respeito da afinação "pelas três" da viola fandangueira do povo do Nhundiaquara. $\bigcirc$ fandango de Morretes se diferencia dos demais fandangos caiçaras por constituir formas de improviso, afinação das violas e formas diferentes de bater o tamanco na dança tradicional da cultura. Foram encontradas informações divergentes descritas na literatura de referências históricas e respeitadas, como o Professor Roberto Corrêa, autoridade que trouxe para o cenário brasileiro o registro das afinações da viola fandangueira. A principal ocorrência da contradição que será apontada ao longo do texto, é a forma com que o autor relata em seu livro (pág. 38) a afinação utilizada pelo violeiro Waldemar Cordeiro, sendo que a afinação apresentada como a "pelas três" no livro do autor é a afinação "pelo meio", tradicional afinação conhecida na llha dos Valadares, Paranaguá (PR). As informações que contrapõe os relatos do autor são oriundas do Dossiê de Registro do Fandango Caiçara: Expressões de um Sistema Cultural, publicado, em dezembro de 2011, pelo Instituto de Patrimônio Histórico e Artístico Nacional (IPHAN). $\bigcirc$ presente artigo tem como intenção registrar, com respeito às obras anteriormente publicadas, a afinação chamada "pelas três" de maior incidência no fandango morretense, corrigindo um equívoco na importante literatura apresentada, a fim de cooperar com 
o reconhecimento cultural e disseminação do conhecimento tradicional do fandango caiçara brasileiro. Por fim, aponta-se para necessidade de pesquisas futuras no sentido de entender quais são as técnicas de execução que diferenciam a viola no sistema "pelas três" dos demais.

Palavras-Chave: viola fandangueira; afinação "Pelas Três"; autoaprendizagem.

\section{Abstract}

This article is a study of the Brazilian Viola used in Fandango of Morretes, State of Parana (PR), with the research's theoretical framework A Arte de Pontear Viola (2002), by Professor Roberto Nunes Corrêa. Its added a descriptive presentation of the self-learning process, developed by the researcher, about viola fandangueira's tuning called "pelas três", typical in the Nhundiaquara people. Morretes's fandango differs from other caiçaras fandangos by have singing improvisations, particular viola's size and tunning and peculiarities in their tap dance. It was found conflicting informations from those described in the historical and respected references literature, such as the Professor Roberto Correa book, authority that brought to the public the written record of several tunings and, among them, the ways to tune the viola fandangueira. The main contradiction pointed in the text, is the way that the author describes the "pelas três" tunning (p.38). Correa (2002) attributes this tuning to the guitarist Waldemar Cordeiro uses; however, this musician plays in "pelo meio" tuning, traditional way of play known on the Valadares Island, Paranaguá (PR). The information that counteracts Roberto Corrêa reports are from the "Dossiê de Registro do Fandango Caiçara: Expressões de um Sistema Cultural" published by the "Institute of Historical and Artistic Heritage National" (IPHAN).. This communication is intended to registrer, with respect to the previously published works, the tuning called "pelas três" correcting a mistake in the important literature presented. It intends, also, to register the viola's construction particularities that took place in Morretes, to cooperate with the cultural recognition and dissemination of traditional knowledge of the Brazilian caiçara fandango. Finally, it points to the need for further to understand what are the techniques that differentiates the viola in the system "pelas três" from the others.

Keywords: viola fandangueira; "Pelas Três" tuning; self-learning.

\section{8}




\section{Lista de figuras}

Figura 1: CRAMANI, D.C. $\bigcirc$ Aprendizado e a prática da rabeca no fandango caiçara: estudo de caso com os rabequistas da família Pereira da comunidade do Ariri. Dissertação apresentada ao Programa de Pós Graduação em Musica. UFPR: 2009, p.48.

Figura 2: CORRÊA, Roberto. A arte de pontear viola. 1. ed. Brasilia, DF: Três Américas, 2000, p 83.

Figura 3: CORRÊA, Roberto. A arte de pontear viola. 1. ed. Brasilia, DF: Três Américas, 2000, p 39.

Figura 4: CORREAA, Roberto. A arte de pontear viola. 1. ed. Brasilia, DF: Três Américas, 2000, p 38.

Figura 5: CORRÊA, Roberto. A arte de pontear viola. 1. ed. Brasilia, DF: Três Américas, 2000, p 39.

Figura 6: CORREA, Roberto. A arte de pontear viola. 1. ed. Brasilia, DF: Três Américas, 2000, p 34.

Figura 7 FERRERO, C.B. Na trilha da viola branca: Aspectos sócioculturais e técnico-musicais do seu uso no fandango de lguape e Cananéia, sp. Dissertação apresentada ao Programa de Pós Graduação em Musica. UNESP: 2007, p. 68.

Figura 8: acervo do autor.

Figura 9: acervo do autor.

Figura 10: acervo do autor.

Figura 11: acervo do autor.

Figura 12: acervo do autor.

Figura 13: CORREAA,J; CRAMANI,D; PIMENTEL,A. (Org.). Museu Vivo do Fandango. Rio de Janeiro: Associação Cultural Caburé, 2006, p.39. 
Figura 14: http://www.giannini.com.br/imgs/produto_ant//884_img.jpg acesso em 01/09/2016.

Figura 15: Acervo do autor.

Figura 16:http://informativo-nossopixirum.blogspot.com.br/2011/1 1/ martinho-dos-santos-um-mestre-do.html acesso em 01/09/2016.

\section{Breve histórico sobre o Fandango Caiçara}

O Fandango Caiçara é uma manifestação que envolve aspectos musicais, coreográficos, poéticos e festivos. Atualmente, ocorre entre - litoral sul do estado de São Paulo, nos municípios de Cananéia e Iguape, e no litoral norte do estado do Paraná, em Guaraqueçaba e Paranaguá - região também chamada de Lagamar. Além destes locais, já foi incidente, também, em Morretes e Antonina, no estado do Paraná, num passado recente (IPHAN, 201 I; CORRÊA; CRAMANI, 2006).

Existem outras regiões do país que possuem expressões populares com nome fandango. Segundo o IPHAN (201 I), o que singulariza o ritmo aqui exposto são as seguintes ações:

a) Práticas que transitam pela fé, parentesco, trabalho e festa;

b) Alternância de danças coreografadas e batidas com tamancos pelos homens, bem como, danças de casais bailadas sem coreografia; e o

c) Universo musical e poético específico, com o uso de instrumentos como a viola fandangueira (ou viola branca, como é conhecida em lguape/SP), com suas afinaçöes e toques caracteristicos, juntamente com adufos e rabecas.

A palavra caiçara designa as comunidades litorâneas formadas pela mescla da contribuição étnico-cultural dos indígenas, dos colonizadores portugueses e, em menor grau, dos escravos africanos. Estas comunidades estão entre uma das primeiras regiões do país colonizadas por ibéricos, datando de 1531, o primeiro contato. Historicamente,

\section{0}


a região experimentou diversos ciclos econômicos de apogeu e decadência, que propiciaram mobilidade espacial dos seus habitantes. Deste processo resultou a miscigenação originária daqueles que hoje são entendidos como caiçaras (DIECUES, 2006).

A prática do fandango acontecia em outras localidades do estado do Paraná, mas, por conta de retaliações diversas, este cenário mudou. Atualmente, se concentra nos litorais dos Estados de São Paulo e Paraná, ao menos desde meados do século XIX (BUDASZ, 2002; DIECUES, 2006; IPHAN, 2011).

A sobrevivência do fandango no litoral deu-se pelo fato de que os grupos que foram deslocados dos centros urbanos mantiveram a força dessa expressão, que sobreviveu em meio a agricultores e pequenos produtores rurais. Prática constante neste grupo social era o "mutirão" (chamado também de pixurum ou ainda pixirão). $\bigcirc$ mutirão era uma forma de trabalho coletiva entre pessoas da comunidade, que se uniam para a derrubada da mata, cuidados com o roçado, puxada de peixe ou varação de canoa. Depois de um dia de trabalho coletivo, um fandango, como forma de pagamento, era oferecido pelo dono da casa ou da terra que havia sido trabalhada, aqueles que o haviam ajudado (CORREAA; CRAMANI, 2006). Era neste espaço também que se faziam as transmissões dos saberes.

Com a modificação do contexto vivenciado pelos caiçaras, dado às leis referentes às Áreas de Preservação Ambientais (APA), estes não podem mais realizar plantio de seu alimento, bem como, são privados de retirarem da mata matéria-prima para construção de seus instrumentos musicais - por exemplo, a caixeta. Desta forma, muitos dos que moravam em sítios se mudaram para regiões que a época os autores chamavam de centros urbanos, cidades como Guaraqueçaba e Paranaguá - esta última cidade abriga grande quantidade de mestres fandangueiros vindos de outras regiões como do litoral sul do Estado de São Paulo.

São constantes as preocupações acerca do fim da referida cultura popular. A falta de contexto para realização do fandango, somado a outros fatores, como a influência dos mais jovens pelas mídias massificadas, a atuação de igrejas neopentecostais que proíbem o fandango e o deslocamento social imposto à figura do velho (BOSI apud CRAMANI, 2009, p. 16) fazem com que esta cultura popular fique restrita, cada vez mais, a um público menor.

\section{1}


Em 1968, Vicente Ulandovski, noticia no jornal $\bigcirc$ Estado do Paraná que o fandango está por acabar, dada a idade avançada dos folgadores (batedores de tamanco) e dos músicos que conduzem os bailes. Por isso, alguns folcloristas e estudiosos começaram a realizar ações de revigoramento. Foi neste intuito que Inami Custódio Pinto, reconhecido folclorista paranaense, se une a Romão Costa, conhecido mestre caiçara, e fundam em 1966 o Grupo de Fandango Mestre Romão (ULANDOVSKI, 1968; GRAMANI, 2009). Grupos de fandango foram, e ainda são formados, com o objetivo específico de estabelecer espaços similares àqueles ocorridos a época em que o fandango estava ligado ao trabalho rural e às festas, para que o ensino e a aprendizagem se dessem de forma ampla e com a manutenção dos saberes transmitidos pelos mais velhos, como ocorria ao final do "mutirão".

\section{Fandango em Morretes}

fandango morretense, assim como nas demais localidades, tem relação com os pixirões e o carnaval e assistiu a redução da sua força com a concomitante diminuição das práticas de mutirão. Na década de 70, sob orientação da professora Helmosa Salomão Ritcher, formouse um grupo que logo encerrou suas atividades com o falecimento da professora nos anos 80 (CORRÊA, 201 1). Como na experiência de Inami Custódio e Mestre Romão, o grupo sustentou as práticas da cultura localmente. Em 2001, formou-se o Grupo de Fandango Professora Helmosa, porém, neste grupo já não haviam músicos que tocassem os instrumentos típicos de um baile de fandango. Apesar disto, se contava com a ajuda esporádica de antigos fandangueiros da região (PIMENTEL; GRAMANI; CORRÊA, 2006).

Do período acima citado datam as preocupações com o fim desta tradição. A jornalista Adélia Lopes (1986) relata, em matéria para o jornal $\bigcirc$ Estado do Paraná que, "os fandangueiros só se apresentavam quando eram chamados para festividades". Segundo os fandangueiros entrevistos pela jornalista, a viola de Morretes se difere das outras presentes no fandango por não possuir a turinal e por ter afinação peculiar que se chama "pelas três". O violeiro, além de performar o acompanhamento, executa pequenos solos - diferente do que acontece

I Turina (também chamada de periquito ou cantadeira), é uma corda a mais, presa na junção do braço com o bojo por uma cravelha até o cavalete. Esta corda não é atingida pela mão que forma os acordes, mas soa a cada vez que o músico tange o instrumento.

\section{2}


em outras localidades, onde os violeiros não executam solos, apenas acompanhamentos.

Manoel da Paz (conhecido como Manequinho da Viola) ex-morador da llha de Valadares, não conseguiria tocar com o Mestre Rufino de França, do grupo de professora Helmosa. Segundo Isidoro, folgador morrentese, entrevistado por Adélia Lopes, os violeiros de Morretes são repentistas, só se repete o estribilho (refrão), quando repetem. Além do mais, são feitas considerações sobre as diferenças na forma de dançar e tamanquear.

Anos após a entrevista, aconteceu um encontro entre fandangueiros das duas localidades, quando Seu Martinho dos Santos ${ }^{2}$ foi chamado para tocar no Festival De Música Cidade Canção (FEMUCIC, 2008) ${ }^{3}$. Os valadarenses Aorélio Domingues, rabequista, e Eloir de Jesus, adufeiro conhecido como Poro, ao acompanhar Seu Martinho apresentaram claras dificuldades em regular a métrica das frases da rabeca com os pequenos interlúdios que Martinho executava, ou seja, acompanhar o mestre fandagueiro que tocava "pelas três", bem como, não conseguiam perceber onde se dava os términos das canções.

No DVD do festival, além da música "Chamarrita" que está no corpo do DVD ainda se apresenta um arquivo extra com outras duas faixas executadas pelos três: "Dondom" e "Bailadinho". É possivel perceber que Martinho improvisa durante parte das músicas, alternando os improvisos com versos prontos. Em outro material, encaminhado por Marcos Malucelli (2015), é possivel encontrar seis modas (Anu, Tonta, Querumana, Chico de Dois, Estrala e Marinheiro) apresentadas por Rufino de França, acompanhado por Januário Cardoso de França, onde se percebem, também, o forte caráter improvisacional deste fandango.

De fato, as únicas informações que se tem sobre esta gravação, feita em fita K7 e digitalizada para arquivos em mp3, por Malucelli, são dadas pelos próprios músicos que estão executando a gravação naquele momento. Nesta gravação, feita na década de 70, Rufino apresenta a si e ao seu companheiro, além de saudar a professora Helmosa, que faz a gravação. Interessante notar que a moda Marinheiro, feita em Morretes, se assemelha muito àquelas de Paranaguá. No entanto, a

2 Matinhos dos Santos foi o último violeiro de fandango de Morretes/Pr que manteve a tradição de construção e execução da viola caiçara na afinação pelas três (foto em anexo).

3 DVD (vídeo) da apresentação encontra-se à disposição em posse do autor do presente artigo.

\section{3}


Chamarrita, por exemplo, é bem diferente do que é possivel se encontrar em outras localidades. Os versos são todos improvisados e a forma de se executar a viola resulta em um acompanhamento onde acontecem frases em terças paralelas, como não podemos observar nas demais afinações da viola caiçara. ${ }^{4}$

\section{As violas fandangueiras}

Desde a década de 30 do século passado, realizam-se pesquisas em torno do Fandango Caiçara. Num primeiro momento houve uma tendência folclorista, seguida por um período com pesquisas etnográficas. Atualmente, existem diversos campos de saberes envolvidos com esta investigação. As pesquisas realizadas que versam sobre os possiveis instrumentos musicais encontrados num baile de fandango, tem em comum que, o instrumento mais importante no baile é a viola fandangueira - ou viola branca (CRAMANI, 2009; IPHAN, 20 I). Ferrero (2007) diz que em lguape e Cananéia, os bailes de fandango são também conhecidos como bailes de viola, tamanha a importância do instrumento.

Segundo Gramani (2009, p. 28):

"A viola é o instrumento presente em todas as localidades em que o fandango acontece. Ela possui peculiaridades locais através da variação do número de cordas, da forma de construção e do nome pelo qual é chamada. São encontradas três formas diferentes de tocar a viola, chamadas pelos fandangueiros de intaivada, pelo meio e pelas tres, que se diferenciam uma das outras principalmente pela posição dos dedos do violeiro no braço do instrumento. No fandango há a utilização basicamente dos acordes de tônica e dominante".

Normalmente, o conjunto musical é formado por duas violas, rabeca e pandeiro. Há inúmeras variações, como o acréscimo de alguns instrumentos musicais a esta formação (p.e. violão) e até a substituição de outros (p.e. o cavaco no lugar da rabeca). As violas, no entanto,

4 relato resulta de pesquisa empírica do presente subscritor que é atualmente, além de pesquisador da cultura no programa de mestrado da UFPR, praticante de viola caipira e viola caiçara da llha dos Valadares pela afinação "intaivada".

\section{4}


não faltam e nunca são substituidas. Elas possuem 5 ordens de cordas ao que se soma, em diversos casos, a turina -característica singular em relação aos outros tipos de violas do Brasil. A confecção do instrumento é, via de regra, feita a partir de caixeta no bojo e canela para as cravelhas, o cavalete e a escala do braço. Entretanto, nada impede a utilização de outros materiais pelos fandangueiros que confeccionam suas próprias violas (observando que nem todos o fazem) e neste momento atua como um luthier.

Apesar de possuir sempre 5 ordens, o número de cordas é variável. É possivel encontrar viola de fandango possuindo desde cinco cordas (cinco ordens simples) até onze cordas (cinco ordens duplas mais a turina). A trasteira vai apenas até o bojo e fica nivelada a ele, contendo apenas dez casas.

Gramani (2009) apresenta a formação dos acordes pela mão esquerda da seguinte forma:

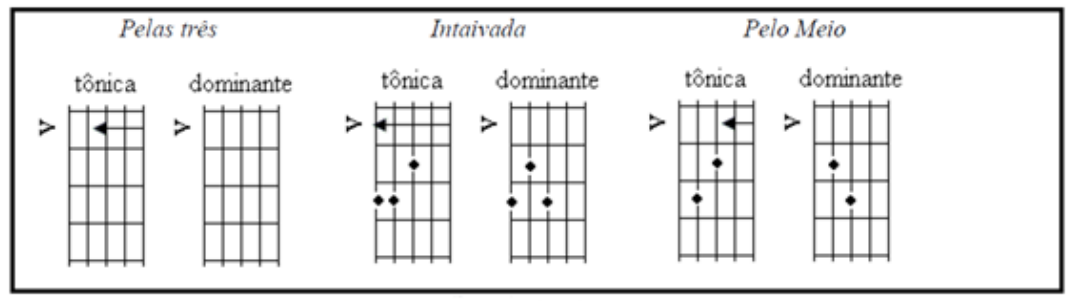

Figura 1: Gramani (2009, p. 48).

Ferrero (2007) encontrou a viola de Cananéia apenas com a afinação "intaivada". A autora salienta que as alturas das cordas (afinações) podem variar, sendo que a referência tomada em seu trabalho é do lá 440HZ (hertz). Assim a afinação, em alguns casos, pode ser mais alta ou mais baixa. Informa, ainda que, o mais importante na afinação do instrumento reside na relação intervalar entre as cordas, ou seja, a diferença de altura entre dois sons ${ }^{5}$, mais do que a altura de referência para a afinaçãó.

5 MED, 2012, p. 60.

6 A escrita adotada para a viola branca neste trabalho é a mesma adotada para a viola caipira e para o violão, ou seja, por comodidade de escrita, se escreve uma oitava acima do som real, utilizando sempre a clave de sol (FERRERO, 2007).

\section{5}




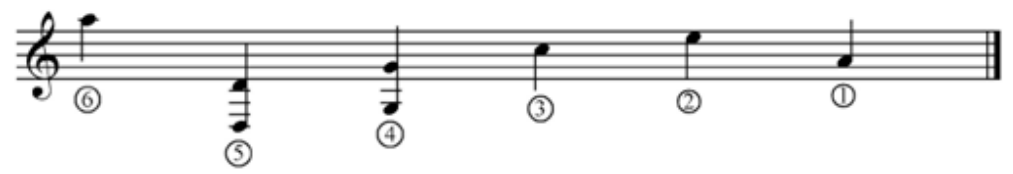

Figura 2: Ferrero (2007 p. 83).

Roberto Corrêa (2002) informa afinações colhidas em Paranaguá, como a de Mestre Ualdemar. No entanto, a informação está equivocada quando o autor afirma, em seu livro, que Waldemar tocava "pelas três" (figura 3) quando é conhecido que tocava na afinação típica da llha dos Valadares, chamada de "pelo meio" (CULIN, 2002; PIMENTEL, GRAMANI, CORRÊA, 2006; IPHAN, 201 I). Assim, Corrêa (2002) faz três escritas de afinações colhidas em campo que descreve da seguinte forma:

Afinação Pelas-Três com o uso da turina:

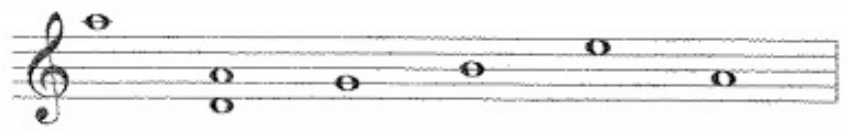

Figura 3: Corrêa (2002 p. 39).

Afinaçio Pelo-Meio:

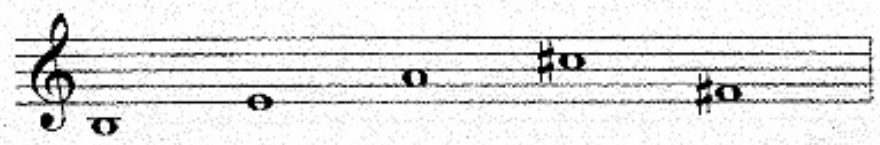

Figura 4: Corrêa (2002 p. 38).

Afinaça Pelo-Meio com o uso da turina:

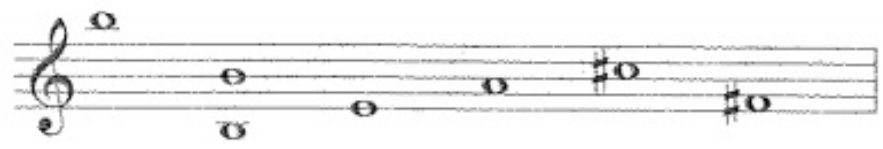

Figura 5: Corrêa (2002 p. 39).

\section{6}


As referências encontradas, como exposto, sobre como se dá a afinação "pelas três" demonstram-se conflitantes. No dossiê preparado para o registro do fandango pelo IPHAN (2011), pode-se encontrar que tal afinação se assemelha à "guitarra". Esta afinação é descrita por Corrêa (2002) da seguinte forma:

\section{Afinação Gtilama, Meta-Guitama:}

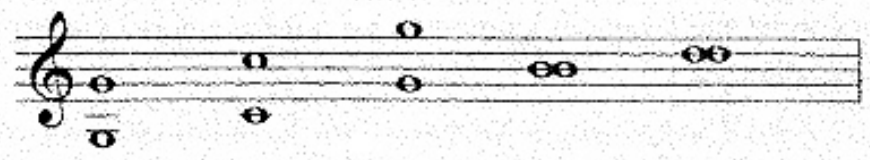

Figura 6: Corrêa (2002 p. 34):

Assim, as informações colhidas e apresentadas até o momento os estudos realizados sobre o fandango, as afinações destacadas, bem como, os conflitos aparentemente existentes - ensejaram tanto a breve pesquisa histórica quanto a crítica do equívoco apresentado no livro de Corrêa (2002) e, ainda, o desenvolvimento do processo cognitivo de autoaprendizagem desenvolvidos pelo presente subscritor, que serão descritas a partir das próximas páginas.

\section{A viola do fandango de Morretes}

As dimensões da viola morretense são bem distinta das demais. Ferrero (2007) apresenta um diagrama onde informa que as medidas das violas de outras localidades de ocorrência do fandango são: 


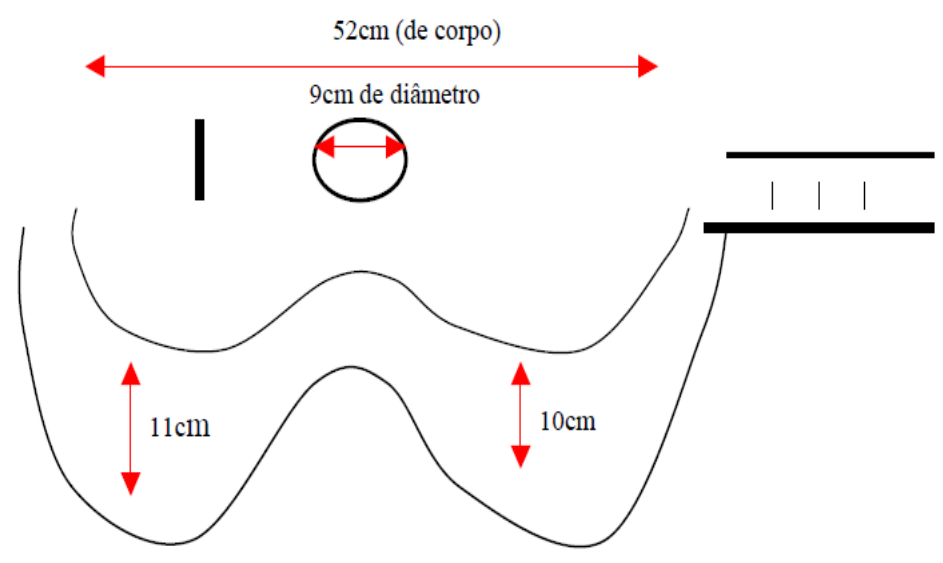

Figura 7: Ferrero (2007 p. 68).

Em busca feita pelo autor na cidade de Morretes e em outras localidades do lagamar, não foi encontrado violas fabricadas por artesãos desta cidade. Seu Martinho fazia as próprias violas e se orgulhava em dizer que já havia fabricado mais de 2000 instrumentos. Foi o último morador de Morretes que construía sua própria viola. Segundo Gramani (2003) a família de Martinho não apoiava a prática de construção de instrumentos e diziam que aquilo the tomava muito tempo. Tempo este que poderia ganhar dinheiro fazendo roçado. No entanto, uma de suas filhas, aprendeu a fazer instrumentos. Em contato com Josiane, filha de Martinho, o presente subscritor a requereu que confeccionasse uma viola, pois ela ainda possuía os moldes e um braço (já com a mão e cravelhas) do pai. Aceitou realizar a construção do instrumento apesar de ter feito várias ressalvas de que não conseguiria fazer igual ao seu pai, mas algo similar.

A viola teve feitio realizado de caroba nas laterais e braço, a escala, o tampo e o fundo foram feitas de compensado, já que não possuía caixeta. Possui $52 \mathrm{~cm}$ de corda, $7 \mathrm{~cm}$ de espessura, 21,5 cm e $30 \mathrm{~cm}$ de distância nas partes arredondadas do tampo e $8 \mathrm{~cm}$ de diâmetro de boca (fotos em anexo). Estas medidas são sensivelmente menores do que as descritas por Ferrero (2007).

\section{8}


Seu Rufino de França e seu Januário, usavam violas industrializadas, violas que se assemelham muito com àquelas fabricadas entre 1950 e 1960, pela Gianini, chamadas de viola paulista números 2 e 6. Segundo o catálogo da década de 60, estas violas eram fabricadas com laterais e fundo em mogno e marfim para as cravelhas, não se cita a madeira do tampo. De acordo com as fotos (em anexo) é possivel levantar a hipótese de que sejam estes os modelos das violas usadas por ambos?.

\section{Descrição do processo de autoaprendizagem da afinação "pelas três"}

Segundo Gohn (2003) a autoaprendizagem é um sistema não formal, porém intencional de se aprender, no qual meios audiovisuais são utilizados como instrumentos de informação musical.

Com uma viola caipira industrializada da marca Hofma, modelo hgb360, em punho, afinada em "guitarra", como descrito por Corrêa (2000), tentou-se afinar as cordas, por imitação e percepção, na mesma altura da viola de Martinho dos Santos, como no vídeo do DVD do festival FEMUCIC (2008). A viola de Martinho soa, neste material audiovisual, próximo a meio tom abaixo do descrito. No entanto, como pontuou Ferrero (2007), é mais importante a relação intervalar do que a altura das cordas, portanto, usaremos como base as alturas da afinação "guitarra" fornecida por Corrêa (2002).

Nos extras do referido DVD, antes de tocar as músicas aparecem pequenos trechos de entrevista onde, enquanto fala, seu Martinho executa o acorde de tônica com o formato descrito por Gramani (2009) - como descrito acima. A primeira percepção de diferença entre a afinação de Martinho e a chamada de "guitarra" é que soa um intervalo muito grave, em quinta, entre os bordões. Empiricamente se achou que o quinto par está em dó, uma quinta a baixo do sol mais grave da afinação "guitarra", e que o quarto par soa como o quinto da referida afinação. Desta forma, a primeira modificação foi afinar os bordões, ficando assim:

7 As medidas destas violas usadas pelos irmãos Rufino e Januário tem medidas muito próximas às praticadas por Seu Martinho. Foi possivel realizar esta comparação já que o autor possui em seu acervo tais violas fabricadas pela empresa Giannini 


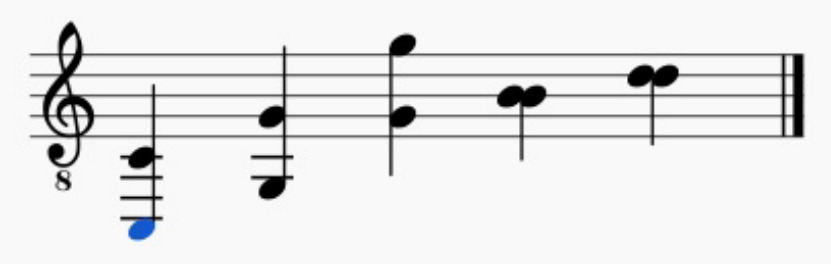

Figura 8.

Feito isso, percebeu-se que Martinho executava um pequeno ornamento harmônico, a partir do seguinte movimento de mãos:
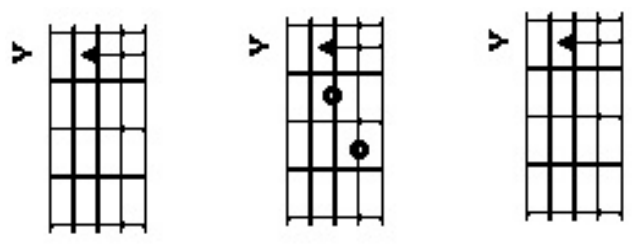

Figura 9.

No entanto, percebeu-se que esse movimento fazia com que se soasse os sons mais agudos da afinação "guitarra". $\bigcirc$ som resultante desse movimento é algo próximo à:

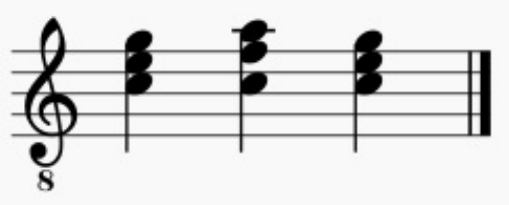

Figura 10.

Isto levou a concluir que as ordens de cordas mais aguda são a $2^{a}$ e a $3^{\circ}$, já que a primeira ordem não foi tocada por nenhum dedo da mão esquerda. Além disto, levou-se a crer que a $1^{\circ}$ ordem é mais grave do que as demais - e sem intervalo de oitava entre as cordas do par. Assim, a segunda alteração em relação à afinação "guitarra" foi, assim, alterar os pares das cordas agudas para resultarem condizentes com o som e o movimento executados por Martinho. Estas alterações levaram à seguinte relação intervalar entre as cordas e os pares:

\section{0}




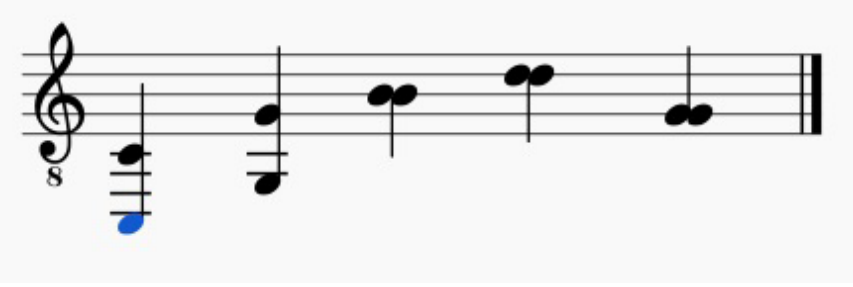

Figura 11 .

Esta alteração permitiu que o som da viola do subscritor ficasse muito próximo do som da viola de Martinho. No vídeo usado como base para esta autoaprendizagem, bem como na foto da página 10 do Guia do Museu Vivo do Fandango (ASSOCIAÇÂO DOS FANDANCUEIROS DO MUNICIPIO DE GUARAQUEÇABA, 2008) pode-se notar que Martinho usa cordas encapadas nos $2^{\circ}, 4^{\circ}$ e $5^{\circ}$ pares. Desta forma, pode-se concluir que a afinação "pelas três" é anotada da seguinte forma:

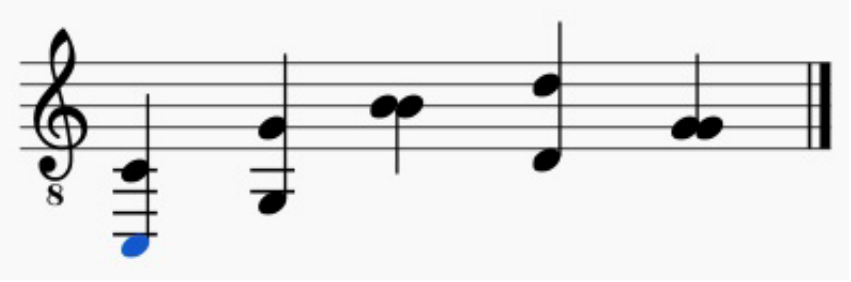

Figura 12

Após achada a afinação, buscou-se tocar juntamente com os áudios dos irmão Rufino e Januário de França (MALUCELLI, 20 15). Constatou-se enorme semelhança entre a afinação aqui encontrada e a usada pela dupla de irmãos. É interessante notar que esta afinação é bem próxima das outras do fandango caiçara. $\bigcirc$ primeiro par soa mais grave que o segundo e o terceiro, o que também é característico das afinações "intaivada" e "pelo meio". Além disto, se elevarmos a afinação "pelas três" em um tom ficaria muito próxima às demais afinações da referida cultura popular.

8 Como é possivel notar nas afinações anotadas por Ferrero (2007) e Roberto Corrêa (2002), respectivamente. 


\section{Considerações Finais}

Em 2012, o Fandango Caiçara foi registrado como Patrimônio Imaterial pelo Instituto de Patrimônio Histórico e Artístico Nacional (IPHAN) com projeto de salvaguarda desta cultura e, em 2014, recebe o certificado de Patrimônio Cultural. No entanto, o seu instrumento mais importante, a viola fandangueira, recebeu pouco estudo e dedicação, e principalmente, poucas investigações que não apenas perpassassem a mera descrição de sua manufatura, partes e afinações; mas, que levem em consideração que a forma de tocar, ou seja, a técnica aplicada pelos fandangueiros, pode se distinguir, significativamente, de uma região para outra, por mais próximas que estejam geograficamente ligadas, como no objeto pesquisado.

É importante dizer que existe relato desta afinação na Barra do Ararapira (PR) com o já falecido Fausto Pires. (IPHAN, 2011; PIMENTEL; CRAMANI; CORREAA, 2006) Exceção feita a este caso isolado, não é descrito na literatura uso desta afinação em qualquer outra região. Morretes não conta mais com os senhores fandangueiros, tocadores e batedores de tamanco, sabe-se pouco sobre sua história.

Neste sentido controlar as "formas costumeiras de transmissão" (Arantes apud Ferrero, 2009) de culturas musicais como a analisada aqui não é sequer possivel no atual contexto social. A transmissão cultural se dava por meio da oralidade, de geração para geração, de modo que suas formas culturais mantinham uma "relação primária-funcional com a vida cotidiana". (OLIVEIRA PINTO; GRAEFF, 2012)

Em ressonância a esta fala, o fandangueiro Dauro do Prado diz à pesquisadora Cintia Ferrero (2007) que, para manter a prática do fandango viva é preciso dar as condições para que o caiçara viva sua cultura: "(...) tem que autorizar eles fazerem a roça, tem que autorizar eles fazerem o manejo de palmito, tem que autorizar eles a fazer o manejo da caxeta (...)".

Pode-se dizer que a autoaprendizagem pode ser um grande aliado na manutenção das culturas tradicionais. É notável que, quando perguntados sobre como aprenderam a tocar, a maioria dos fandangueiros responde que foi olhando os mais velhos e reproduzindo, a sós 
e escondidos 9 . Talvez este seja mesmo o processo de transmissão tradicional caiçara. A este processo soma-se a escuta constante do ritmo a partir das paisagens sonoras (SCHAFER, 200 I) dos encontros (mutirões). Atualmente, pela impossibilidade deste procedimento, fandangueiros tem sugerido que se escute os CDs gravados por eles ${ }^{10}$.

Há muito trabalho a ser realizado, ainda há muita pesquisa que deve ser feita em relação ao fandango de forma geral, e, em particular, o de Morretes. Preservar este passado, ainda pouco explorado e carente de pesquisas, só é possivel se se encontrar algum fandangueiro que tenha na memória as práticas desta cultura. Ainda se faz necessário, em pesquisa posterior, entender qual é a forma de condução harmônica feita nesta afinação, quais sãos as frases em terças praticadas pelos violeiros e como esta afinação pode se adequar as práticas do fandango hodiernas.

\section{Referências Bibliográficas}

ASSOCIAÇÃO DOS FANDANCUEIROS DO MUNICÍPIO DE CUARAQUEÇABA. Guia Museu vivo do Fandango. Guaraqueçaba: Associação dos Fandangueiros do Município de Guaraqueçaba, 2008. saltério.

BUDASZ, R. Música. In: SANTOS, A. V. dos. Cifras de música para

Curitiba: UFPR, 2002. p. 18-32.

CORREAA, J.; CRAMANI, D. Naquele tempo, no tempo de hoje: um panorama do fandango no litoral norte do Paraná e sul de São Paulo. In: CORREEA,J; GRAMANII,D; PIMENTEL,A. (Org.). Museu Vivo do Fandango. Rio de Janeiro: Associação Cultural Caburé, 2006. p. 21-37.

CORRÊA, J. R. O. ; Entre Valsados e batidos: a dança do Fandango Caiçara nos sítios e palcos. In: Encontro Internacional de Antropologia e Performance, 201 1, São Paulo. Encontro Internacional de Antropologia e Performance, 2011

9 Vide Pimentel; Gramani; Corrêa, 2006.

10 Gramani (2009, p. 103). 
CORREAA, Roberto. A arte de pontear viola. 1. ed. Brasilia, DF: Três Américas, 2000. 259 p., il.

DIECUES, A. C.(Org.). Enciclopédia Caiçara, vol. I, O Olhar do Pesquisador. São Paulo: Editora HUCITEC-NUPAUB-CEC/NSP, 2004.

DIECUES, A. C. Cultura e Meio-Ambiente na região estuarina de Iguape-Cananéia-Paranaguá. . In: CORRÊA,J; CRAMANI,D; PIMENTEL,A. (Org.). Museu Vivo do Fandango. Rio de Janeiro: Associação Cultural Caburé, 2006. p. 13-19.

FESTIVAL DE MÚSICA CIDADE CANÇÃO (FEMUCIC). FEMUCIC: 30 anos. Maringá, PR: SESC Paraná, 2008. I DVD, digital.

FERRERO, C.B. Na trilha da viola branca: Aspectos sócio-culturais e técnico-musicais do seu uso no fandango de lguape e Cananéia, sp. Dissertação apresentada ao Programa de Pós Graduação em Musica. UNESP: 2007.

$\mathrm{GOHN}$, Daniel Marcondes. Auto-Aprendizagem Musical: Alternativas Tecnológicas. 1. ed. São Paulo: Annablume Editora, 2003. v. 1.21 l p.

CRAMANI, D.C. O Aprendizado e a prática da rabeca no fandango caiçara: estudo de caso com os rabequistas da familia Pereira da comunidade do Ariri. Dissertação apresentada ao Programa de Pós Graduação em Musica. UFPR: 2009.

CRAMANI, Jose Eduardo. Rabeca o som inesperado. Curitiba, PR: Arcádia Livraria \& Eventos de Arte, 2003. il.

GULIN, Rogério. Fandango da Família Pereira. In: Marchi, Lia, Saenger, Júlia \& Corrêa, Roberto. Tocadores. Curitiba: Palloti, 2002.

INSTITUTO DO PATRIMÔNIO HISTÓRICO E ARTÍSTICO NACIONAL (IPHAN). Texto Descritivo Completo - Fandango Caiçara: Expressões de um Sistema Cultural, elaborado pela Associação Cultural Caburé, dezembro de 2011.

LOPES, A.M. Batendo o fandango com os folgadeiros de Morretes. In: $O$ Estado do Paraná, Caderno Almanaque, 27/07/1986. 
MALUCELLI, MP.F. Modas Antigas. mfmalucelli@hotmail.com. 19/11/2015.

MED, Bohumil. Teoria da Música. 4ª . Ed. Revista Ampliada. São Paulo: Musimed, 2012.

PIMENTEL, Alexandre; CRAMANI, Daniella; CORRÊA, Joana (Org.). Museu vivo do fandango. Rio de Janeiro, RJ: Associação Cultural Caburé, 2006. 199 p., 32 cm. 2001.

SCHAFER, M. A Afinação Do Mundo. São Paulo: Editora da UNESP,

ULANDOVSKI. V. Paraná faz festival sem mostrar folclore. IN: O Estado do Paraná. Curitiba 22/08/1968.

\section{Sobre o autor}

Frederico Conçalves Pedrosa é Bacharel em Musicoterapia pela Faculdade de Artes do Paraná (2010) e mestrando em Música pela Universidade Federal do Paraná. Atua em pesquisa nas áreas de musicoterapia, saúde coletiva, cognição musical e Fandango Caiçara. Atualmente é professor colaborador do curso de Bacharelado em Musicoterapia na Universidade Estadual do Paraná. Participa dos grupos de pesquisa Processos Formativos e Cognitivos em Educação Musical, PROFCEM-CNPa, e do Núcleo de Estudos e Pesquisas Interdisciplinares em Musicoterapia, NEPIM-CNPa. Participou do projeto de extensão Música dos Povos com o grupo Omundô e fez parte do grupo Jazz Cigano Quinteto onde estudou a linguagem musical de diferentes etnias do globo. Atualmente participa da Orquestra Rabecônica do Brasil e dos grupos Paranambuco e Chamegado nos quais estuda a linguagem musical das culturas tradicionais brasileiras.

Lattes: http://lattes.cnpa.br/9227 | 38663195042

Recebido em: $11 / 09 / 2016$

Aprovado em: 15/12/2016 


\section{Anexos}

Professora Helmosa junto aos violeiros Januário e Rufino França:

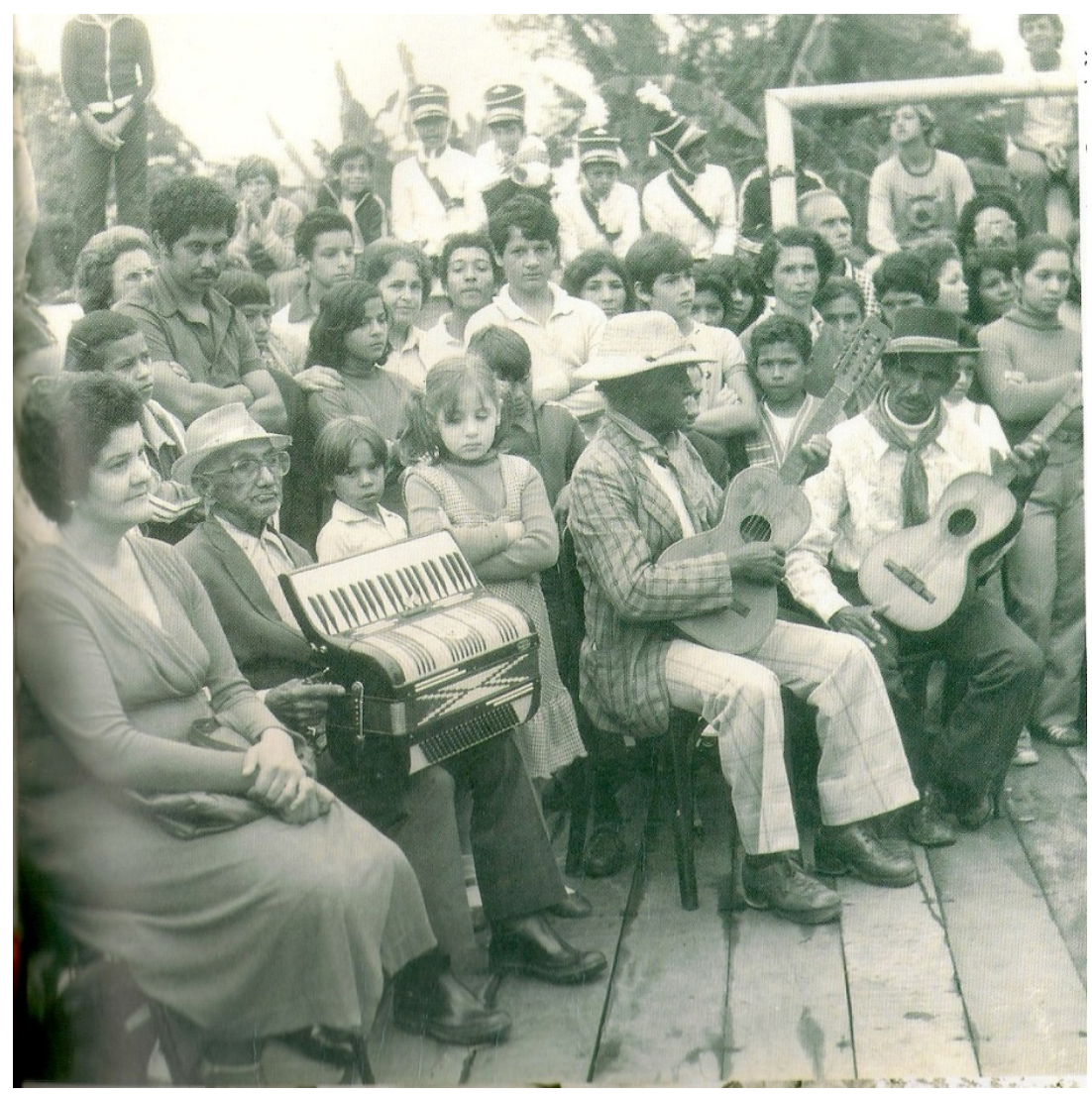

Figura 13: PIMENTEL; CRAMANI, CORREAA (2006, p.39) 
Catálogo Tranquillo Giannini de 1960:

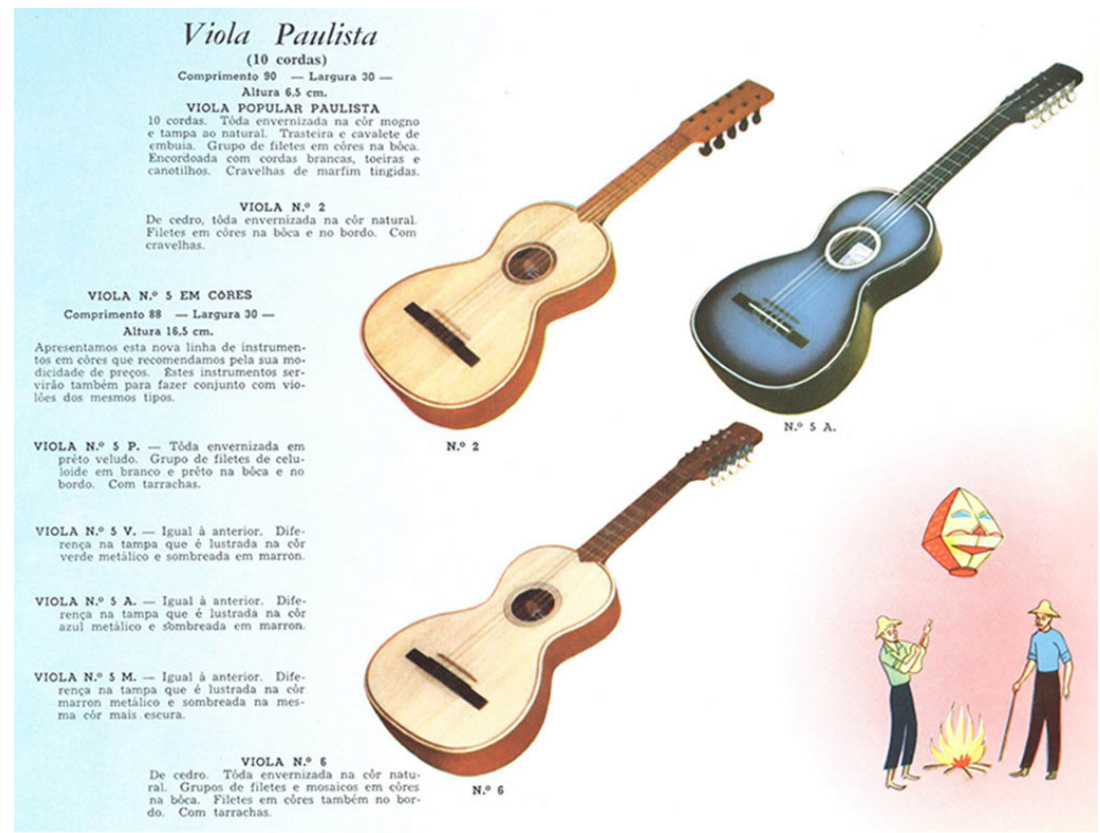

Figura | 4: http://www.giannini.com.br/imgs/produto_ant//884_img.jpg acesso em $01 / 09 / 2016$ 
Josiane Santos, Frederico Pedrosa e Cristiano Santos:

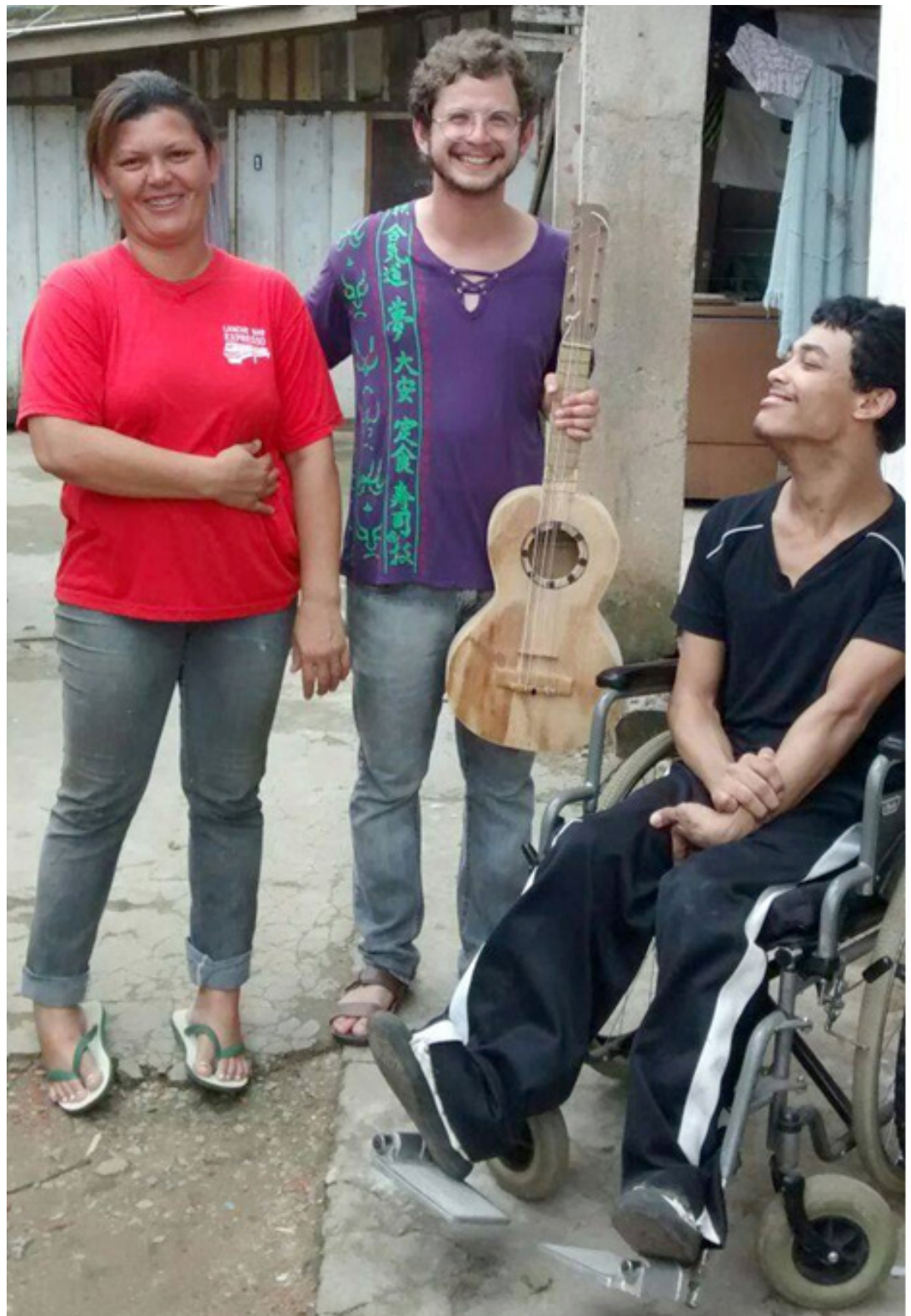

Figura 15: Acervo do autor

\section{8}

REV. TULHA, RIBEIRÃO PRETO, v. 2, n. 2, p. 177-199, jul.-dez. 2016 
Seu Martinho e sua viola:

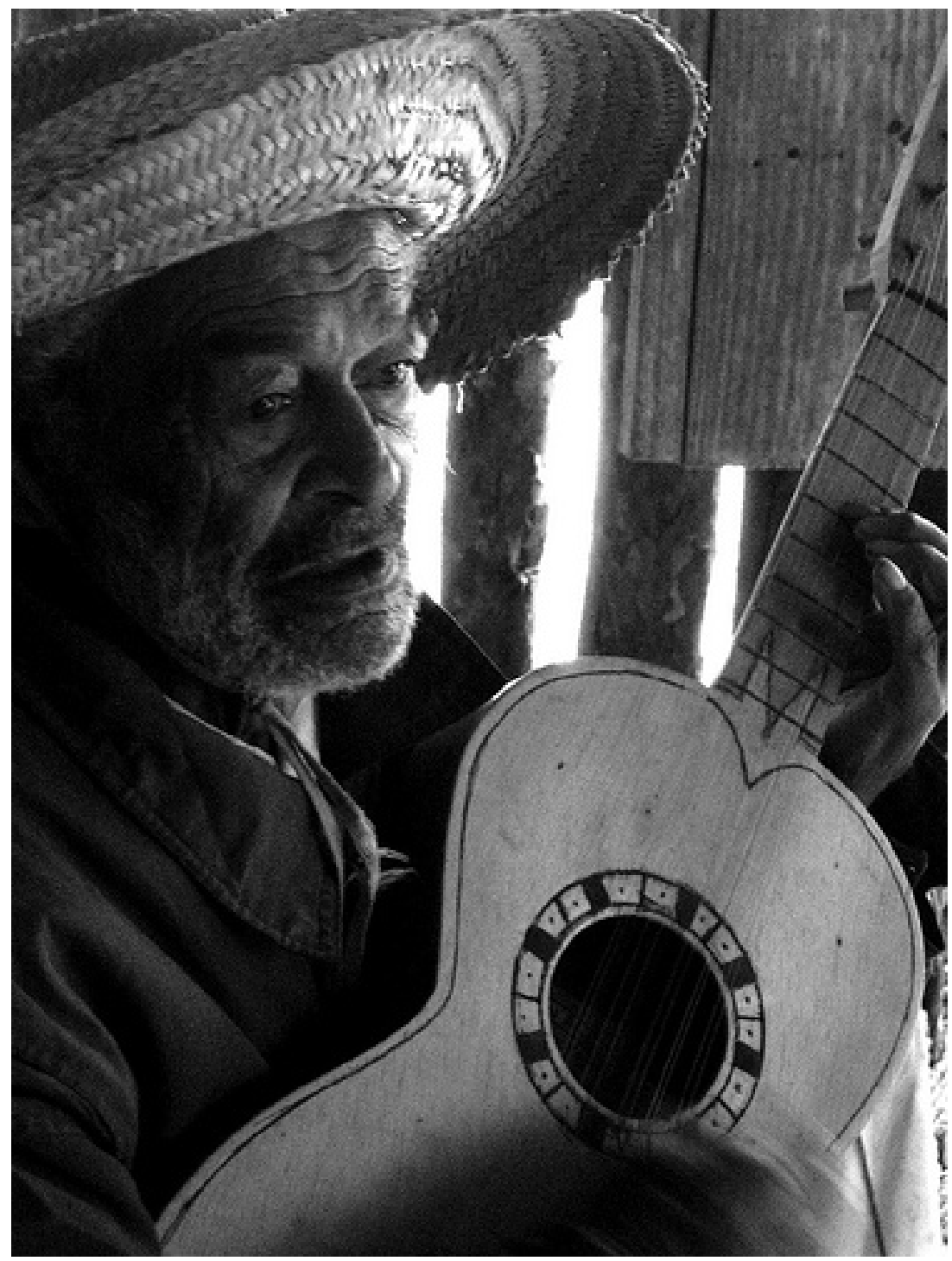

Figura 16: http://informativo-nossopixirum.blogspot.com.br/20 1 1/1 1/martinho-dos-santosum-mestre-do.html acesso em 0l/09/2016.

\section{9}

REV. TULHA, RIBEIRÃO PRETO, v. 2, n. 2, p. 177-199, jul.-dez. 2016 